\title{
Valuing endoscopic papillary large-balloon dilation and direct cholangioscopy in a "small-stones-in-large-bile-duct" situation
}

\author{
Vincent Zimmer ${ }^{\mathrm{a}, \mathrm{b}}$ \\ Marienhausklinik St. Josef Kohlhof, Neunkirchen; Saarland University Medical Center, Saarland University, Homburg, Germany
}

An 87-year-old patient post-cholecystectomy presented with right upper quadrant pain and mild cholestasis. With a history of endoscopic retrograde cholangiopancreatography (ERCP) with papillotomy and common bile duct dilation (CBD) on ultrasound, the patient underwent repeat ERCP. Despite an intradiverticular localization and diffusely reddened, slightly elevated papillary mucosa (post hoc adenoma excluded) (Fig. 1A), cannulation was uncomplicated, confirming a 20-mm diameter CBD without definitive stones (Fig. 1B). Balloon and 8-wire Dormia basket (FlowerBasket, Olympus) sweeps proved ineffective; however, contrast clearance appeared reduced and the papillary orifice shrunken. Therefore, endoscopic papillary large-balloon dilation up to $13.5 \mathrm{~mm}$ was performed (Fig. 1C) for treatment of intradiverticular post-papillotomy stenosis and priming for direct cholangioscopy (DC). The latter might potentially be considered the novel golden standard in bile duct stone detection and/or exclusion, particularly in the presence of diffuse biliary dilation [1,2]. Likewise, immediate stone passage might be induced, as indeed occurred in the presented case after balloon retrieval and luminal suctioning (Fig. 1D). After switching to an ultra-slim upper endoscope (Fujinon EG$530 \mathrm{NW}$, outer diameter $5.9 \mathrm{~mm}$ ), the large-bore papillary orifice (Fig. 2A) was intubated in a freehand fashion, revealing some fresh blood in the pre-papillary segment (Fig. 2B). After an intensified J maneuver and intermittent epigastric compression to reduce gastric loop formation, with the patient in left lateral position (our standard position in DC candidates), full DC was accomplished and remnant stone disease excluded in the distal (Fig. 2C,D) and the proximal CBD up to the hilum (Fig. 2E,F).

${ }^{a}$ Department of Medicine, Marienhausklinik St. Josef Kohlhof, Neunkirchen (Vincent Zimmer); bepartment of Medicine II, Saarland University Medical Center, Saarland University, Homburg (Vincent Zimmer), Germany

Conflict of Interest: None

Correspondence to: Dr. Vincent Zimmer, Department of Medicine, Marienhausklinik St. Josef Kohlhof, Klinikweg 1-5, 66539 Neunkirchen, Germany, e-mail: vincent.zimmer@gmx.de

Received 22 May 2020; accepted 25 May 2020; published online 20 June 2020

DOI: https://doi.org/10.20524/aog.2020.0520

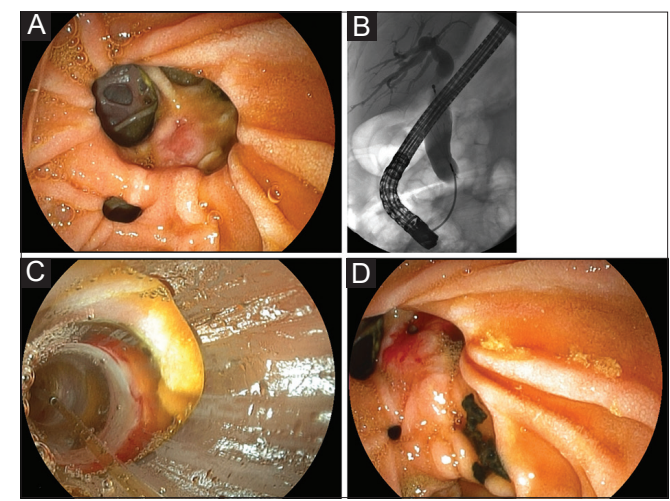

Figure 1 (A) Intradiverticular localization of the diffusely reddened, slightly elevated papilla with a shrunken orifice post-papillotomy (post hoc pathologic exclusion of adenoma). (B) Cholangiogram with a markedly dilated common bile duct and ineffective balloon (not shown) and 8-wire Dormia basket sweeps. (C) Endoscopic papillary large-balloon dilation up to $13.5 \mathrm{~mm}$, (D) resulting in spontaneous passage of several small pigment stones

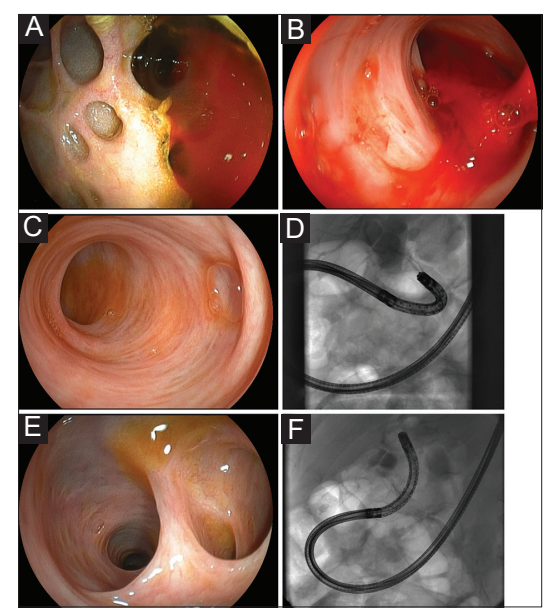

Figure 2 (A) Large papillary orifice (lower right) before freehand intubation with an ultra-slim upper endoscope. (B) Small amounts of blood in the prepapillary common bile duct (CBD). (C, D) Exclusion of remnant stones in the distal and $(\mathrm{E}, \mathrm{F})$ the remaining $\mathrm{CBD}$ during scope advancement up to the liver hilum (endoscopic-fluoroscopic juxtapositions, respectively)

\section{References}

1. Anderloni A, Auriemma F, Fugazza A, et al. Direct peroral cholangioscopy in the management of difficult biliary stones: a new tool to confirm common bile duct clearance. Results of a preliminary study. J Gastrointestin Liver Dis 2019;28:89-94.

2. Zimmer V. ERC vs. direct cholangioscopy: Dawn of a new reference standard. Dig Liver Dis 2018;50:199. 